Portland State University

PDXScholar

February 2005

\title{
Adolescents Growing Up in Stressful Environments, Dual Diagnosis, and Sources of Success
}

\author{
Albert R. Roberts \\ Rutgers University \\ Kevin Corcoran \\ Portland State University
}

Follow this and additional works at: https://pdxscholar.library.pdx.edu/socwork_fac

Part of the Social Work Commons

Let us know how access to this document benefits you.

\section{Citation Details}

Adolescents growing up in stressful environments, dual diagnosis, and sources of success. Brief treatment and crisis intervention,5(1), 1-8. (with A.R. Roberts)

This Article is brought to you for free and open access. It has been accepted for inclusion in School of Social Work Faculty Publications and Presentations by an authorized administrator of PDXScholar. Please contact us if we can make this document more accessible: pdxscholar@pdx.edu. 


\title{
Adolescents Growing Up in Stressful Environments, Dual Diagnosis, and Sources of Success
}

\author{
Albert R. Roberts, PhD, DABFE \\ Kevin Corcoran, PhD, JD
}

This article considers the social and psychological challenges to youth in contemporary society. The authors examine the variety of social impediments that face youths in most of our social institutions, from schools and the juvenile justice system to the family. They underscore the need for prevention, health promotion, and comprehensive assessment. Further, they assert that "dual diagnosis" needs to be considered not as a "special population" but as the typical or common experience of at-risk youths once they are diagnosed at mental health centers or juvenile justice reception and diagnostic centers. They conclude that evidence-based assessment, intervention, prevention, and health promotion will start to unravel the matter of misdirected diagnosis and treatment. The articles in this special issue amply illustrate what can be done. [Brief Treatment and Crisis Intervention 5:1-8 (2005)]

KEY WORDS: adolescence, youths, drug abuse, dual diagnosis, school violence, ADHD, $A D D$, juvenile justice, comorbid mental disorders.

Every year millions of youths experience illicit drug use, alcoholism, depression, school violence, urban stressors, acute psychotic episodes, suicidal ideation, intimate partner violence, unplanned pregnancy, and a seemingly endless

From the Criminal Justice Department at Rutgers University (Roberts), and the Graduate School of Social Work, Portland (Oregon) State University (Corcoran).

Contact author: Dr. Albert R. Roberts, Rutgers University, Livingston College Campus, Lucy Stone Hall, B wing, Room 261, 54 Joyce Kilmer Avenue, Piscataway, NJ 08854. E-mail: prof.albertroberts@comcast.net.

doi:10.1093/brief-treatment/mhi009 list of biological, psychological, and social challenges. The seriousness of these prevalent social and public health problems is made clear by the stark reality of street lives, in terms of drugs and prostitution, bullying and mass violence in schools, truancy and school dropouts, juvenile delinquency and gang violence, attention deficit hyperactivity disorder (ADHD) and other learning disabilities, domestic violence, runaways, and throwaways. A recent 5-year longitudinal study of 1,103 youths and young adults between the ages of 14 and 25 found that homeless and substance-abusing

Brief Treatment and Crisis Intervention Vol. 5 No. 1, (c) Oxford University Press 2005; all rights reserved. 
street youth had a mortality rate from suicide, drug overdoses, and HIV infection that was 11 times that of youth in the general population (Abdalian, 2004).

Millions of youths suffer from ADHD or attention deficit disorder (ADD) without hyperactivity. Specifically, they are easily distracted, impulsive, talkative, impatient, interruptive of others, and late most of the time; tend to procrastinate; and seem to have inappropriate behavior. On the other hand, some persons with ADHD or ADD also have significant qualities, like the ability to hyperfocus when something interests them, creativity, boundless energy, and the ability to persevere against the odds. As a result, some ADDers become famous authors, professors, inventors, musicians, clinical psychologists, child psychiatrists, social workers, actors, criminologists, and/or CEOs. And yet, many others become public school and college dropouts, habitual delinquents, career criminals, or marginalized persons in society, such as welfare recipients or the homeless. Obviously, family supports and positive adult role models play a part in whether youths become productive citizens or career criminals. However, it is very difficult to determine how a dynamic teacher, minister, coach, family member, or neighbor can help youths to overcome the effects of ADD or the harsh and mean streets of poverty, incompetent schoolteachers, gangs, drug dealers, pimps, child abuse, and sexual assaults pervasive in urban areas throughout the United States. In 1968 the late Dr. Walter Reckless, criminology professor at Ohio State University, found in a longitudinal study that high selfesteem among youths was an insulator against delinquency and crime. This occurred regardless of the fact that the subjects in the study all grew up in poor inner-city neighborhoods of Columbus, Ohio. This seminal study, however, does not tell us how to turn around the downward spiral in a youngster's self-concept once a crisis escalates and the unmet need for rapid assessment and treatment begins.

\section{Case Examples}

Rolando is a 16-year-old youth who has been diagnosed with schizophrenia, including command hallucinations over the past 2 days telling him to kill his brother. This has happened before, and according to the client records Rolando becomes actively psychotic and violent after stopping his psychiatric medication. Rolando's mother calls the 24-hour mobile crisis unit for children and adolescents. For further information on mobile crisis intervention and stabilization of this case, see Jonathan Singer's article in this special issue.

John is a 16 year old with a history of mental illness and drug abuse. This case has been complicated by John's receiving inconsistent treatment for his emergent comorbid mental illness and substance abuse. $\mathrm{He}$ has been adjudicated by the juvenile court seven times in the past 3 years for possession of illicit drugs, theft, and assault and is now facing additional serious legal consequences. For further information on this case, see Roberts and Yeager's drug treatment article in this issue of the journal.

Joan is a 14-year-old pregnant youth who is being held in the county youth correctional facility for stabbing her boyfriend, Ted. She has stated that Ted, who is 19 years of age and an alcoholic, beat her several times during the past year that they have lived together. However, when Ted learned that Joan was 4 months pregnant, he tried to kill the fetus by kicking her in the stomach. Joan felt she had no choice but to stab Ted several times in order to protect her fetus.

Christine is 15 years old and has run away from home because of repeated sexual assaults from her stepfather and older brother. Although Christine is highly anxious and depressed and 
has attempted suicide twice, she would rather be homeless and involved in prostitution than be repeatedly sexually assaulted in her home.

\section{Etiology and Treatment}

All four youths lack positive coping skills, family supports, and the benefits of evidencebased assessments and treatments. For a nation committed to the health - mental and physicaland welfare of its people, including future generations, we cannot limit ourselves to afterthe-fact interventions such as temporary shelters, group homes, and large, Bastille-like juvenile institutions. Prevention and health promotion surely must enter the formula somewhere! The articles in this special issue and the rich descriptions of crisis events and youths' failed coping methods underscore the urgent need for the development of psychometrically sound assessment measures, evidence-based treatment protocols, psychosocial and life skills training, and prevention strategies.

The time is ripe for twenty-first-century clinicians and researchers to stop viewing troubled youths with mental disorders through a psychopathology lens. In recent years, growing attention has been given to strengths-based intervention models, such as early assessment and case finding, solution-focused therapy, 24hour mobile crisis intervention, primary prevention programs, social skills curricula, and ego bolstering of youths by clinicians utilizing motivational interviewing, the stages-of-change model, resilience and protective factors, multisystemic family treatment, cognitive-behavioral treatment, and mindfulness approaches.

In the area of etiology, is it a pileup of stressful life events or an intense stressor like child sexual abuse or pressure to join a gang, or is it one brief, yet intense traumatic event (e.g., physical assault, threat at knifepoint, failing a course needed for graduation) that precipitates an acute crisis episode? Individuals escalating into an acute crisis state perceive that they are falling apart mentally, cannot function and make rational decisions, are confused and unbalanced, and do not know where or how to get help. It is not just a traumatic event or chronic stressor or an accumulation of urban stressors; it is also based on the individual's limited problem-solving abilities and coping skills. One example on the topic is Miller and Townsend's article in this special issue for a new perspective on measuring chronic stressors and their impact on adolescent mental health through the Urban Hassles Index. The second example is Chun and Springer's article on concept mapping, as well as stress and coping strategies that are needed in order to fully understand adolescent runaways in crisis.

\section{Assessment and Comorbid Mental Disorders}

School social workers and counselors, behavioral health clinicians, psychologists, and psychiatric residents should all be well versed in the use of standardized assessment measures and instruments with children. Assessment instruments serve several important functions, such as screening for early detection of problems and intervention; assessment of problems, coping efficacy, magnitude of a crisis, urban hassles, chronic stressors, type and severity of mental disorders, and diagnosis in the $D i$ agnostic and Statistical Manual of Mental Disorders; and assessment of behavioral changes during the course of treatment (LeCroy \& Okamoto, 2002; Lewis \& Roberts, 2002). Recently, researchers and clinicians in both mental health and juvenile justice settings have found that the majority of adolescents arriving at mental health centers and juvenile justice reception centers have two or more comorbid disorders. At the Fall 2004 annual conference of 
the American Association of Behavior Therapy (AABT), a number of presentations focused on the growing evidence in clinical settings that comorbidity among children and youth is the norm rather than the exception. Similarly, the article by Corcoran in this special issue illustrates that the average youth in the juvenile justice system presents with about seven serious mental health symptoms.

There is an absence of published rapid assessment instruments useful for identifying the numerous mental health problems among youths in an all-inclusive manner. Corcoran's Oregon Youth Mental Health Referral Checklist (OMHRC) is thorough and inclusive, including perspectives of the parent, the mental health professional, and the youth, and was developed to assess the critical needs of today's youth. In his article, Corcoran discusses the psychometric properties of his new scale and indicates how it can be used to scrupulously evaluate the youth's mental health and crisis-oriented situation. Along with the well developed and widely used Achenbach's (1997) Child Behavior Checklist, the OMHRC is one of the few assessment tools designed for use by the youth, parents, and relevant others, including teachers and staff in the juvenile justice system. One of the major strengths of the OMHRC is that it is a rapid assessment instrument and can be completed relatively quickly.

The notion that there is a special population or subpopulation with "dual diagnoses" seems to us to be completely incorrect. From our combined experience of over 60 years working with youths in a variety of settings - including detention centers, jails, prisons, juvenile correctional facilities, mental hospitals, group homes, drug treatment centers, crisis hotlines, youth service bureaus, domestic violence work, and police social work-we believe that the opposite is true. Youths with dual diagnosis, once they are in need of services, are far from a sub- or special population. In our opinion, the unique population are the youths with a single diagnosis, social, or behavioral problem. The typical youngster in critical need of service is the one with dual diagnoses and multiple social, behavioral, or familial problems. All too often, the common thread that binds the mental health problems together is drugs or alcohol.

As a result, it becomes even more imperative to use psychometrically rigorous and standardized assessment instruments. For example, according to David Springer, misdiagnosing acting-out behavior and effects of poverty as conduct disorder, or confusing symptoms of ADHD with bipolar disorder can have very serious consequences during treatment. The medications that are effective with bipolar disorder cannot be interchanged with the medications for ADHD (Springer, 2002).

The most overlooked component of the assessment process is assessing the adolescent's strengths. The risk of schizophrenia rises from less than $1 \%$ in the general population to more than $30 \%$ for those who have two schizophrenic parents. Turning this around, though, is the fact that $70 \%$ of children with "bad genes" and a chaotic home environment grow up quite normally. What enables them to do so, and what are we missing in our assessments? For example, does the youth persist in handling family crises, follow through on decisions, use resourcefulness despite limited resources, seek to improve self through education and skill building, consider and weigh alternatives in problem solving, have a sense of humor, show acceptance of others, and/or want to improve current and future situations? Is the youth positive and hopeful about life, verbally fluent, ambitious, a good listener, outgoing and friendly, cooperative, and nonjudgmental (Cowger \& Snively, 2002)? Surely if this century's advances in the behavioral and social sciences are to include prevention and health promotion, assessment of both risk factors and protective factors is critical. Both problems and 
symptomatology as well as strengths and resiliency factors must be ascertained.

\section{Drug Abuse and Youths}

The crisis of drug abuse and addiction among adolescents today is complex and challenging. Today's youths are faced with unprecedented access to illicit drugs that cause brain damage, active psychosis, suicide attempts, homicidal thoughts, and repeat violence. The most frequently used drugs among adolescents and young adults are marijuana and alcohol, followed at much less prevalence by cocaine, methamphetamine and Ecstasy (3,4-methylene dioxymethamphetamine, or MDMA), and heroin. According to the Substance Abuse and Mental Health Services Administration, substance abuse is highest among 12th graders, among whom 1 in $4(25.7 \%)$ use illicit drugs. In addition, $14.8 \%$ of 8 th graders have tried some illicit drug other than marijuana by the end of the 8 th grade, and $10.8 \%$ have abused amphetamine compounds. All too often, youths are rushed to the emergency room of their local medical centers in a stupor or a delusional, trancelike, semiconscious, or unconscious state after ingesting or snorting large amounts of illegal drugs. Very often, these youths have no idea what they have taken, except that they were green, blue, yellow, or orange little pills that gave them a rush and made them high before they collapsed. For up-to-date information on adolescent crisis intervention and evidence-based substance abuse treatment, see Roberts and Yeager's article in this special issue. Also, please refer to the lead author's Web site: http://www.crisisinterventionnetwork.com.

\section{School Problems and Violence}

The problems facing today's young people are exacerbated by violence. The violence may be between and among them and their families, but we have to be aware of the secondary effects of living, learning, and playing in violent settings. It is difficult for most adults to understand how a youth would deeply believe and intensely feel the need to carry a weapon to school or the playground for protection. The explanation is the proliferation of violent youth gangs pervasive in urban areas and recently spreading to many suburbs. A recent research report of over 22,000 adolescents, 11 to 15 years of age, indicated that both United States ( $41 \%$ ) and Israeli students $(42 \%)$ were bullied in the past school term, while only $14 \%$ of Swedish students were bullied. Occasional fighting seemed to be the norm among youths studied in all five countries - the United States, Ireland, Israel, Portugal, and Sweden - and the average number of injuries during a fight was almost the same in all five countries, slightly over $15 \%$ of the students involved in a fight. In sharp contrast, American youths are much more likely to be killed than are the adolescents studied in the other developed countries. The researchers from the National Institute of Child Health and Human Development (NICHD), one of the National Institutes of Health (NIH), indicated that possible explanations for the higher violencerelated mortality among youths in the United States include their greater and easier access to lethal weapons and different attitudes toward life and death than youth in the other countries studied (Smith-Khuri et al., 2004).

It seems that between direct experiences and the secondary impact of the social environment, the siege on our youth is considerably violent. According to the National Center for Injury Prevention and Control of the Centers for Disease Control and Prevention, in the year 2000 over 400,000 children and youths 10-19 years of age were injured as a result of violent acts. Food fights and assaults in school cafeterias, carrying a weapon to school, and bullying on school buses and in the hallways 
lead the list of school problems in many urban and suburban public middle schools and high schools. Approximately $9 \%$ of students aged 10-19 reported that they were intentionally slapped, punched, kicked, or physically injured by a boyfriend or a girlfriend in the past 12 months. Vandalism, shootings, and stabbings seem to occur most frequently soon after school lets out at 3 p.m., and the most frequent time period for these incidents is between 3 and 5 p.m. Parents, students, and teachers are very interested in promoting safer schools based on proven interventions that last beyond the ringing of the afternoon school bell. The main problem is that there is not enough educational technology in the public schools, and there are too few learning specialists and school social workers employed at each school who could implement support groups for students with learning disabilities, divorced or separated parents, substance abuse problems, mental health problems, pregnancies, and so on. An equally important deficit is the curricula in most secondary schools, which lack content on conflict resolution, prevention of bullying, and social skills. The United States could learn a lot from Australian educators who have implemented bullying prevention programs starting in the fifth grade. For detailed information on school-based secondary violence prevention programs, see the article by Molina, Dulmus, and Sowers in this special issue. Prevention is clearly the key to addressing youth violence in both its direct and indirect surroundings.

\section{Juvenile Offenders With Mental Health Problems}

In many states and provinces throughout the United States and Canada, research estimates have indicated that the majority of juvenile offenders have one or more diagnosed or undiagnosed mental disorders. More specifi- cally, approximately two thirds of juvenile detainees confined in county and city detention centers have one or more mental disorders (Rapp-Palicchi \& Roberts, 2004). The most prevalent mental disorders among juvenile offenders, in order of frequency, are conduct disorders, chemical dependency, ADHD, and affective disorders (bipolar disorder and depression, antisocial personality disorder, borderline personality disorder, and psychosis). Most juvenile offenders are dual diagnosed, and few present with a single problem or symptom.

Because many of the youths adjudicated to the juvenile justice system in their respective states have concurrent mental health issues, it is imperative that all of these youths receive thorough biopsychosocial assessments to identify any mental health problems and/or learning disabilities (Rapp-Palicchi \& Roberts, 2004). Youths with undetected and undiagnosed mental health problems who are confined in juvenile detention, juvenile training schools, or boot camps can decompensate over time as a result of the stressful environment and strict discipline. Gangs exist in every major city and county throughout the United States. They also exist in most large juvenile detention and correctional institutions. The largest and most notorious illegal street gangs are the Bloods, the Crips, and the Latin Kings. These gangs have a growing influence on children and youths through movies and through music videos and their lyrics. In order to assess the strong influence of music videos and their lyrics on youths today, just ask any youngster about Snoop Dogg, Ice Cube, Lil Bow Wow, Death Row Records, gang affiliations, or drive-by shootings and he or she will provide you with complete details (Jackson, 2003). Any notion of rehabilitation is thwarted by mental health conditions (Corcoran, Washington, \& Meyers, in press). A group of these youths are at high risk for 
suicide and assaultive behavior, especially if they are impulsive, have poor judgment, and are depressed. The juvenile justice system critically needs trained mental health professionals. Unfortunately, a number of states are not interested in recruiting doctoral-level psychologists; and even when they are, the starting salary is pretty dismal. For example, the New Jersey Training School at Jamesburg incarcerates 274 juveniles and employs 191 custodial officers/guards with a starting salary of $\$ 65,000$ per year, despite the fact that these guards have only a high school diploma or GED. In sharp contrast, this juvenile institution has three doctoral-level psychologists on staff with a starting salary of $\$ 43,000$. The entry-level salary for correctional teachers, vocational instructors, and those with master's in social work is $\$ 42,000$.

\section{Evidence-Based Treatment}

According to Roberts and Yeager (2004), evidence-based practice can be defined as practitioners' conscientious, explicit, and judicious utilization of the best available and scientifically validated assessment, intervention, and treatment protocols as well as critical thinking in making clinical decisions. Corcoran and Vandiver (2004) aptly point out that evidence-based practice is a process of using a variety of databases to locate the most useful sources of information - systematic reviews, practice guidelines, and expert consensus guidelines - applied to a particularly challenging client. They also note that implementing evidence-based information and guidelines in practice settings "will likely strengthen a treatment plan, and in turn, will increase the likelihood of client change and goal attainment, ... enhancing treatment effectiveness" (p. 17). In recent years, the implementation of best practices and evidence-based treatments with children and youths has grown. A number of evidence-based studies have found that individual and group cognitive-behavioral treatment has been effective with youths suffering with anxiety disorders; skills training and individual cognitive therapy have been effective with youths diagnosed with depression or dysthymia; videotape-based parent training and multisystemic therapy have been effective with youths with conduct disorders; and behavior management and positive reinforcement point systems or token economy have been effective in reducing ADHD symptoms (Okamoto \& LeCroy, 2004).

The challenges considered here are addressed in the articles of this special issue on brief treatment and crisis intervention with adolescents. The articles are evidence-based and datadriven assessments and recommendations for interventions and prevention/health promotion. We believe that the challenges to our youth are so many and so great that we must use the best available methods. These articles reflect these methods.

In conclusion, this is not to necessarily say that future generations literally depend on it. That would overstate the case and be nonsense, as the future depends on nothing but time. More modestly and far less dramatically, we believe that the quality of life at school and at home for many of our youths does require facing formidable challenges successfully. We know personally and professionally how this makes a difference in terms of whether a youngster in need of crisis intervention, a role model, or ego bolstering becomes a CEO, professor, or attorney, or marginalized, unemployed, and homeless.

\section{References}

Abdalian, S. E. 2004. Street youth mortality: Leaning with intent to fall. Journal of the American Medical Association, 292(5), 624-626. 
Achenbach, T. M. (1997). Manual for the youth self-report and youth adult behavior checklist. Burlington, VT: University of Vermont Department of Psychiatry.

Corcoran, K., \& Vandiver, V. (2004). Implementing best practice and expert consensus procedures. In A. Roberts \& K. Yeager (Eds.), Evidence-based practice manual (pp. 15-19). New York: Oxford University Press.

Corcoran, K., Washington, T. A., \& Meyers, N. (in press). The impact of gang membership on mental health symptoms, behavior problems and antisocial criminality of incarcerated young men. Journal of Gang Research.

Cowger, C. D., \& Snively, C. A. (2002). Assessing client strengths. In A. Roberts \& G. Greene (Eds.), Social workers' desk reference (pp. 221-225). New York: Oxford University Press.

Jackson, M. (2003). Law enforcement officers' response to illegal street gang activity. In A. R. Roberts (Ed.), Critical issues in crime and justice (2nd ed.) (pp. 35-50). Thousand Oaks, CA: Sage Publications.

LeCroy, C. W., \& Okamoto, S. K. (2002). Guidelines for selecting and using assessment tools with children. In A. Roberts \& G. Greene (Eds.), Social workers' desk reference (pp. 213-216). New York: Oxford University Press.

Lewis, S. J., \& Roberts, A. R. (2002). Crisis assessment tools. In A. Roberts \& G. Greene
(Eds.), Social workers' desk reference (pp. 208-212). New York: Oxford University Press.

Okamoto, S. K., \& LeCroy, C. W. (2004). Evidence-based practice and manualized treatment with children. In A. Roberts \& K. Yeager (Eds.), Evidence-based practice manual (pp. 246-252). New York: Oxford University Press.

Rapp-Palicchi, L., \& Roberts, A. R. (2004). Mental illness and juvenile offending. In A. R. Roberts (Ed.), Juvenile justice sourcebook: Past, present and future (pp. 289-307). New York: Oxford University Press.

Roberts, A. R., \& Yeager, K. (2004). Systematic reviews of evidence-based studies and practicebased research: How to search for, develop, and use them. In A. R. Roberts \& K. Yeager (Eds.), Evidence-based practice manual (pp. 3-14). New York: Oxford University Press.

Smith-Khuri, E., Iachan, R., Scheidt, P. C., Overpeck, M. D., Gabhainn, S. N., Pickett, W., et al. (2004). A cross-national study of violence-related behaviors in adolescents. Archives of Pediatrics \& Adolescent Medicine, 158(6), 539-544.

Springer, D. W. (2002). Assessment protocols and rapid assessment instruments with troubled adolescents. In A. Roberts \& G. Greene (Eds.), Social workers' desk reference (pp. 217-221). New York: Oxford University Press. 